\title{
Retrospective analysis of vitamin D status on inflammatory markers and course of the disease in patients with COVID-19 infection
}

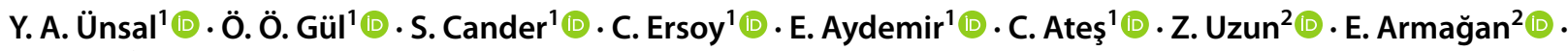 \\ O. Ünsal ${ }^{3}$ (D) E. Ertürk ${ }^{1}$
}

Received: 28 December 2020 / Accepted: 29 March 2021 / Published online: 5 April 2021

(C) Italian Society of Endocrinology (SIE) 2021

\begin{abstract}
Purpose The aim of the study was to investigate the association between serum 25 -hydroxyvitamin D status within the last 6 months prior to COVID-19 infection and parameters of immune function and clinical outcomes.

Methods Fifty-six patients, who were admitted to the emergency clinic and diagnosed with COVID-19 infection, were included in the study. Data on clinical characteristics, inflammatory parameters and vitamin D status were recorded for each patient. All the participants had data on 25-hydroxyvitamin D status within the last 6 months prior to COVID-19 infection. Results The patients were stratified as those with vitamin D status less than $20 \mathrm{ng} / \mathrm{mL}$ and higher than $20 \mathrm{ng} / \mathrm{mL}$. A group with vitamin D status less than $20 \mathrm{ng} / \mathrm{mL}$ had lower lymphocyte counts and lower haemoglobin levels that was statistically significant (respectively; $p=0.021, p=0.035$ ). Higher C-reactive protein (CRP) levels were seen in the vitamin D-deficient group ( $p=0.013$ ). It was observed that vitamin $\mathrm{D}$ status of the patients who required oxygen therapy were lower than those who did not require oxygen therapy, not statistically significant $(p=0.05)$. Patients who did not use vitamin $\mathrm{D}$ supplementation within 6 months prior to COVID-19 infection had more likely to be diagnosed with pneumonia $(p=0.004)$.

Conclusion Cases with lower vitamin D status had increased inflammatory markers and worse clinical outcomes than patients with higher vitamin D status. This study suggests that vitamin D status can be used as a prognostic factor in COVID-19 patients, and vitamin D supplementation can be recommended to improve the clinical outcomes in COVID-19 infection.
\end{abstract}

Keywords Vitamin D $\cdot$ COVID-19 $\cdot$ Immunity $\cdot$ Anti-inflammatory $\cdot$ Pneumonia

Y. A. Ünsal

yaseminunsalay@gmail.com

Ö. Ö. Gül

drozenoz@gmail.com

S. Cander

drcander@gmail.com

C. Ersoy

ecanan@uludag.edu.tr

E. Aydemir

ensaraydemir@gmail.com

C. Ateş

drcsknates@gmail.com

Z. Uzun

drziyauzun61@gmail.com
E. Armağan

earmagan9999@yahoo.com

O. Ünsal

oktayunsal@uludag.edu.tr

E. Ertürk

erturkerdinc@gmail.com

1 Faculty of Medicine, Department of Endocrinology and Diseases of Metabolism, Bursa Uludag University, Bursa, Turkey

2 Faculty of Medicine, Emergency Department, Bursa Uludag University, Bursa, Turkey

3 Faculty of Medicine, Oncology Department, Ankara Gazi University, Ankara, Turkey 


\section{Introduction}

A novel coronavirus, called severe acute respiratory syndrome coronavirus 2 (SARS-CoV-2), as a cause of pneumonia cases that has affected the healthcare systems across the world in late 2019 [1]. As the SARS-CoV-2 virus has high levels of transmissibility, and the disease spread quickly to all over world, World Health Organisation (WHO) declared the outbreak as the public health emergency [2].

The spectrum of infection is highly heterogeneous, from asymptomatic cases to cases with multiple organ dysfunctions have been seen and fewer than $15 \%$ of the cases develop severe disease [3-5]. People older than 60 years, males, Black, Hispanic and South Asian and with pre-existing comorbidities such as cardiovascular disease, diabetes mellitus, hypertension, chronic lung disease, cancer, chronic kidney disease, obesity and smoking are more vulnerable to severe form of the disease [6-10].

Vitamin $\mathrm{D}$ is one of the factors that may be linked to the severity of COVID-19. Vitamin D deficiency is pandemic like COVID-19, and it has become a global problem. The best laboratory indicator of vitamin $\mathrm{D}$ deficiency is serum 25-hydroxyvitamin $\mathrm{D}[25(\mathrm{OH})$ vitamin $\mathrm{D}]$ concentration [11]. The Institute of Medicine suggests that serum 25 $(\mathrm{OH})$ vitamin D concentration of $20 \mathrm{ng} / \mathrm{mL}$ is sufficient for most individuals, but Endocrine Society and National Osteoporosis Foundation say that a minimum level of $30 \mathrm{ng} / \mathrm{mL}$ is necessary to minimise the risk of falls and fracture $[12,13]$.

Vitamin D is important for bone health and calcium-phosphorus metabolism. It plays a role in the modulation of the immune response in autoimmune diseases $[14,15]$. Many tissues in the skeletal system and intestine and cells in the bone marrow, brain, colon, breast, malignant cells and also immune cells express vitamin D receptor [16]; this suggests that vitamin D plays a role in the immune system. In one study that includes 19,000 subjects between 1988 and 1994, it was revealed that individuals with lower vitamin $\mathrm{D}$ status $(<30 \mathrm{ng} / \mathrm{mL})$ had been more likely to have a recent upper respiratory tract infection than others [17]. Many studies reported an association between vitamin $\mathrm{D}$ status and infections such as influenza, bacterial vaginosis and human immunodeficiency virus. These studies reported an association of lower vitamin D status and increased rates of infection [16, 18, 19].

Vitamin D plays a role in both innate and adaptive immunity [20]. The innate immune system is the defence against invading pathogens, such as SARS-CoV-2 virus. Active vitamin $\mathrm{D}\left[1,25(\mathrm{OH})_{2} \mathrm{D}\right]$ induces antimicrobial peptides such as cathelicidin that leads to viral destruction, killing and clearance of these pathogens by neutrophils, monocytes/macrophages and dendritic cells, and then the adaptive immune response is initiated [21, 22]. Chronic activation of the innate immune response can result in a cytokine storm. Active vitamin D can downregulate chronic innate immune response via downregulation of toll-like receptors and direction inhibition of tumour necrosis factor/nuclear factor-kappa B (TNF/NF- $\mathrm{KB})$ and interferon-gamma (IFN- $\gamma$ ) signalling pathways. Also, $1,25(\mathrm{OH})_{2} \mathrm{D}$ regulates adaptive immunity by limiting the maturation of dendritic cells and reduces their ability to present antigen to $\mathrm{T}$ cells. It causes shifting the T-cell profile from the pro-inflammatory $\mathrm{T}$ helper cell type 1 (Th1) and Th17 subsets to Th2 and T regulatory cell (Treg) subsets and so that the expression of anti-inflammatory cytokines such as interleukin-1alpha (IL-1 $\alpha$ ) and TNF- $\alpha$ are reduced [23]. Furthermore, SARS-CoV-2 enters into pneumocytes and enterocytes by binding with angiotensinconverting enzyme 2 (ACE-2) on the surface of the cells. Vitamin D downregulates ACE-2 so that it inhibits the action of the virus [24, 25]. Recent studies on COVID-19 and vitamin $\mathrm{D}$ indicates an association between low 25 $(\mathrm{OH})$ vitamin D status and clinical outcomes of the infection [26, 27].

This study evaluated the association between $25(\mathrm{OH})$ vitamin D status and inflammatory markers, clinical outcomes, mortality in cases with positive result for COVID-19 infection and data on $25(\mathrm{OH})$ vitamin D status within the last 6 months.

\section{Materials and methods}

\section{Patients and data source}

Fifty-six patients, who had admitted to the emergency clinic of Uludag University Faculty of Medicine Hospital and diagnosed with COVID-19 infection between March 2020 and October 2020, were included in the study. All the participants had data on $25(\mathrm{OH})$ vitamin D within the last 6 months prior to COVID-19 infection. Time frame of the measurement of $25(\mathrm{OH})$ vitamin D was $3(1-6)$ months. Patients diagnosed with COVID-19 infection between March 2020 and October 2020 were included in this study to minimise the sunlight effect that can change status. This study did not include patients who had measured $25(\mathrm{OH})$ vitamin $\mathrm{D}$ status at any time. The study protocol was approved by ethics committee of Uludag University Faculty of Medicine (2020-20/10).

\section{Data collection and laboratory analysis}

Data such as age, gender, weight, height, smoking status, prior vitamin D supplementation, symptoms of infection, 
comorbidities and reports of chest X-ray and chest computed tomography were provided from the hospital database.

Biochemical and haematological laboratory parameters on hospital admission were recorded. Data on $25(\mathrm{OH})$ vitamin $\mathrm{D}$, which was measured in the last 6 months, were obtained from the same hospital database (Uludag University Faculty of Medicine) with the same assay by chemiluminescence immunoassay method. SARS-CoV-2 infection was confirmed in all patients of COVID-19 by reverse transcription-polymerase chain reaction (RT-PCR) on nasopharyngeal swabs.

\section{Statistical analysis}

Statistical analyses were performed using the SPSS software version 15 . The variables were investigated using visual (histograms) and analytical methods (Kolmogorov-Smirnov/ Shapiro-Wilk test) to determine the normal distribution. Descriptive analyses were performed using medians for non-normally distributed and ordinal variables. The categorical data were shown in counts and percentages. Non-parametric tests were conducted to compare these parameters and the ordinal variables. The chi-squared test or Fisher's exact test (when chi-squared test assumptions do not hold because of low expected cell counts), where appropriate, was used the compare the proportions in different groups. A $p$ value of less than 0.05 was considered to show a statistically significant result.

\section{Results}

A total of fifty-six patients were included in this study. Median age of patients was 44 years (26-76 years). Approximately $67.9 \%$ of patients were female and $26.8 \%$ of the cases were evaluated as obese [body mass index $(\mathrm{BMI}) \geq 30 \mathrm{~kg}$ / $\mathrm{m}^{2}$ ]. It was learned from the anamnesis that $78.5 \%$ of the patients had never smoked. These patients had a history of chronic disorder; $21.4 \%$ had hypertension, $19.6 \%$ had diabetes, $17.9 \%$ had depressive disorder, $16.1 \%$ had asthma, $16.1 \%$ had hypothyroidism, $12.5 \%$ had malignancy, $8.9 \%$ had coronary artery disease, $8.9 \%$ had hyperlipidaemia and $5.4 \%$ had chronic kidney disease. Also, $3.6 \%$ of patients had chronic obstructive lung disease, and $3.6 \%$ of patients were followed-up with a diagnosis of chronic liver disease. The baseline characteristics of patients are presented in Table 1.

Only one person had no symptoms of infection at the time of admission. He was admitted to emergency outpatient clinic because of the family history of COVID-19 PCR positivity. Cough was found to be the most common symptom, as described by the COVID-19 patients. Malaise (44.6\%), myalgia (44.6\%), fever (39.3\%), anosmia (39.3\%), ageusia $(35.7 \%)$, shortness of breath $(30.4 \%)$, sore throat
Table 1 Demographics, comorbities of COVID-19 patients

\begin{tabular}{lc}
\hline Characteristic & Results \\
\hline Age, median (year) & $44(26-76)$ \\
Sex $(n) /(\%)$ & \\
Female & $38(67.9)$ \\
Male & $18(32.1)$ \\
Body mass index $\left(\mathrm{kg} / \mathrm{m}^{2}\right)$ & \\
$\geq 30(n)(\%)$ & $15(26.8)$ \\
$<30(n)(\%)$ & $36(64.3)$ \\
Smokers $(n) /(\%)$ & \\
Never smoke & $44(78.6)$ \\
Current or former smoker & $12(21.4)$ \\
Comorbidity $(n) /(\%)$ & \\
Hypertension & $12(21.4)$ \\
Diabetes mellitus & $11(19.6)$ \\
Depressive disorder & $10(17.9)$ \\
Asthma & $9(16.1)$ \\
Hypothyroidism & $9(16.1)$ \\
Malignancy & $7(12.5)$ \\
Coronary artery disease & $5(8.9)$ \\
Hyperlipidemia & $5(8.9)$ \\
Chronic kidney disease & $3(5.4)$ \\
Chronic obstructive lung disease & $2(3.6)$ \\
Chronic liver disease & $2(3.6)$ \\
25 (OH) vitamin D $(\mathrm{ng} / \mathrm{mL})$ & \\
$<20$ ng/ml $(n)(\%)$ & $27(48.2)$ \\
$\geq 20$ ng/ml $(n)(\%)$ & $29(51.8)$ \\
\hline
\end{tabular}

Numerical variables were expressed as median and categorical variables were presented as percentages

$25(\mathrm{OH})$ vitamin $\mathrm{D} 25$ hydroxyvitamin D

(28.6\%), diarrhoea (21.4\%), nausea/vomiting (19.6\%), headache $(17.9 \%)$ and arthralgia (17.9\%) were the other common symptoms, as described by the patients.

Median status of $25(\mathrm{OH})$ vitamin D was $21.5 \mathrm{ng} / \mathrm{mL}$ (6.6-51 ng/mL). Twenty-seven patients $(48.2 \%)$ had 25 $(\mathrm{OH})$ vitamin D status less than $20 \mathrm{ng} / \mathrm{mL}, 51.8 \%$ of patients (29 patients) had $25(\mathrm{OH})$ vitamin D status higher than or equal to $20 \mathrm{ng} / \mathrm{mL}$. Patients were stratified as vitamin D normal $(\geq 20 \mathrm{ng} / \mathrm{mL})$ and deficient $(<20 \mathrm{ng} / \mathrm{mL})$ groups. When inflammatory markers were compared between the two groups, higher C-reactive protein (CRP) levels were seen in the vitamin D-deficient group $(p=0.013)$. Procalcitonin levels were also found to be higher in the vitamin D-deficient group that was not statistically significant $(p=0.074)$ (Table 2). Although D-dimer levels of the two groups were not different, these were found to be significantly higher $(p=0.025)$ in patients with vitamin D status less than or equal to $10 \mathrm{ng} / \mathrm{mL}$.

No patients were followed-up in the intensive care unit (ICU), $51.8 \%$ of patients were admitted to inpatient clinic. 
Table 2 Some laboratory parameters of COVID-19 patients in relation to vitamin D status

\begin{tabular}{lccc}
\hline Parameter & \multicolumn{2}{l}{ Vitamin D status } & \multirow{2}{*}{$p$ value } \\
\cline { 2 - 3 } & $<20 \mathrm{ng} / \mathrm{ml}$ & $\geq 20 \mathrm{ng} / \mathrm{ml}$ & \\
\hline White blood cell $(\mathrm{C} / \mathrm{ml})$ & $5665(2960-17,810)$ & $5590(1370-10,530)$ & 0.769 \\
Neutrophils $(\mathrm{C} / \mathrm{ml})$ & $3520(1303-4666)$ & $3320(940-8603)$ & 0.315 \\
Lymphocyte $(\mathrm{C} / \mathrm{ml})$ & $1140(370-2481)$ & $1550(290-3254)$ & 0.021 \\
Neutrophil/lymphocyte ratio & $3.8(0.73-13.81)$ & $2.53(0.81-12.06)$ & 0.018 \\
C-reactive protein $(\mathrm{CRP})(\mathrm{mg} / \mathrm{L})$ & $18.4(2-294.4)$ & $4.45(2-67.9)$ & 0.013 \\
Erythrocyte sedimentation ratio $(\mathrm{mm} / \mathrm{saat})$ & $37(2-87)$ & $20(1.09-47)$ & 0.440 \\
Procalcitonin( $\mu \mathrm{gg} / \mathrm{L})$ & $0.04(0-0.97)$ & $0.02(0-1.09)$ & 0.074 \\
Ferritin $(\mathrm{mg} / \mathrm{dL})$ & $67.6(4.2-6167)$ & $62.5(4.1-309)$ & 0.779 \\
Albumin $(\mathrm{g} / \mathrm{L})$ & $33(4-46)$ & $41(4.4-49)$ & 0.413 \\
Fibrinojen $(\mathrm{mg} / \mathrm{dL})$ & $483.9(242.6-697.4)$ & $306(121.1-564)$ & 0.361 \\
D-dimer $(\mathrm{mg} / \mathrm{L})$ & $0.45(0.17-16.27)$ & $0.35(0.17-1.9)$ & 0.111 \\
\hline
\end{tabular}

Table 3 Outcomes analysis of the patients

\begin{tabular}{lc}
\hline Parameters & Patient number/(\%) \\
\hline Respiratory support (number) & $47(83.9)$ \\
No requirement & $5(8.9)$ \\
Low-flow nasal oxygen therapy & $3(5.4)$ \\
High-flow nasal oxygen therapy & $1(1.8)$ \\
Invasive mechanical ventilation & $18(32.1)$ \\
Pneumonia & \\
Hospitalization status & $29(51.8)$ \\
Hospitalized & $27(48.2)$ \\
Outpatient clinic management & \\
Treatments & $40(71.4)$ \\
Favipravir & $35(62.5)$ \\
Hydroxychloroquine & $24(42.9)$ \\
Antimicrobial therapies & $22(39.3)$ \\
Heparin & $11(19.6)$ \\
Glucocorticoids & $6(10.7)$ \\
Plasmapheresis & $5(5)$ \\
Oseltamivir & $2(3.6)$ \\
Tocilizumab & $2(3.6)$ \\
Mortality &
\end{tabular}

Numerical variables were expressed as median and categorical variables were presented as percentages

Median time of hospital stay was 10 days (2-35 days) and there was no difference in the median time of hospital stay between vitamin D subgroups. Outcomes analysis of the patients are presented in Table 3. Although $47 \%$ of all patients did not need any respiratory support, $1.8 \%$ of cases need invasive mechanical ventilation. Vitamin D status of the cases who need oxygen therapy was found to be lower than those who did not need oxygen but not significant $(p=0.05)$ (Table 4).

Many of the vitamin D-deficient patients $(50 \%$ of the cases) were on vitamin D supplementation average
Table 4 Requirement of respiratory support according to vitamin D status

\begin{tabular}{lll}
\hline $25(\mathrm{OH})$ vitamin D levels & \multicolumn{2}{l}{ Requirement of respiratory support } \\
\cline { 2 - 3 } & No need $(n)(\%)$ & $\begin{array}{l}\text { Need to } \\
\text { support }(n) \\
(\%)\end{array}$ \\
\hline$<20 \mathrm{ng} / \mathrm{ml}$ & $20(42.6)$ & $7(77.8)$ \\
$\geq 20 \mathrm{ng} / \mathrm{ml}$ & $27(57.4)$ & $2(22.2)$ \\
\hline
\end{tabular}

Table 5 Usage of vitamin D supplementation and diagnosis of pneumonia

\begin{tabular}{lcc}
\hline \multirow{2}{*}{$\begin{array}{l}\text { Usage of vitamin D supple- } \\
\text { mentation }\end{array}$} & \multicolumn{2}{l}{ Diagnosis of pneumonia } \\
\cline { 2 - 3 } & Yes $(n)(\%)$ & No $(n)(\%)$ \\
\hline Yes & $4(22.2)$ & $24(63.2)$ \\
No & $14(77.8)$ & $14(36.8)$ \\
\hline
\end{tabular}

Vitamin D supplementation Average 800-1000 IU/day with cholecalciferol

$800-1000 \mathrm{IU} /$ day with cholecalciferol and were likely to be repleted. The patients with supplementation were found to be higher $25(\mathrm{OH})$ vitamin D status than others, which was statistically significant $[p=0.03 ; 25.5(6-51) \mathrm{ng} / \mathrm{mL}, 16.9$ (6-40.4) $\mathrm{ng} / \mathrm{mL}$, respectively]. Pneumonia was observed in $22.2 \%$ of the patients who used vitamin D supplementation; $77.8 \%$ of the patients who did not use vitamin D supplementation were diagnosed with pneumonia $(p=0.004)$ (Table 5).

Two patients (3.6\%) died because of COVID-19 infection; these patients were not followed up in the ICU because they were ineligible to ICU, but during the follow-up severity of lung involvement rapidly increased. Because of the rapid deterioration of the patients, they died before being taken to ICU. $25(\mathrm{OH})$ vitamin D status of these cases were found to be less than $20 \mathrm{ng} / \mathrm{mL}$. 


\section{Discussion}

COVID-19 infection is an increasing global health problem, and many studies have been done to evaluate the modifiable risk factors. Many retrospective studies had determined the correlation between vitamin $\mathrm{D}$ status and COVID-19 [28]. Vitamin D is a steroid hormone and plays an important role in bone-mineral metabolism and immunity. Many studies have emphasised a correlation between vitamin D deficiency and various diseases, including systemic infections [29-31]. Vitamin D stimulates secretion of antiviral peptides, which improves physical barrier to viruses. It also stimulates cellular immunity by decreasing the cytokine storm with influence on IFN- $\gamma$ and TNF- $\alpha$ and regulates adaptive immunity through inhibiting Th1 responses [32, 33].

Cao and his colleagues have reported high incidence of lymphopenia in COVID-19 patients [34]. Lymphocyte percentage in the patients of this study with vitamin $\mathrm{D}$ status less than $20 \mathrm{ng} / \mathrm{mL}$ was found to be lower than others that is considered as immunomodulatory effect of vitamin D. Lymphopenia can be seen in COVID-19 patients because of many reasons: increased expression of the coronavirus receptor ACE-2 by lymphocytes makes them target for COVID infection. Also, TNF- $\alpha$, IL-6 and other pro-inflammatory cytokines and elevated lactic acid levels interfere with proliferation of lymphocytes. Liu et al. noticed that the neutrophil-to-lymphocyte ratio (NLR) could be an independent risk factor for critical illness in patients with COVID-19 infection. In that prospective study, 61 COVID-19 cases were evaluated, and the NLR values were found to be higher in the severe or critical group on admission [35]. Median neutrophil/lymphocyte ratio in this study was found to be significantly lower in the group with vitamin D status higher than or equal to $20 \mathrm{ng} / \mathrm{mL}$ that can be because of higher lymphocyte counts in this group ( $p=0.018)$.

Studies demonstrated that a lower haemoglobin level was associated with more severe COVID-19 disease course. This situation can be attributed to inflammation associated with COVID-19. In acute inflammation, cytokines-induced iron metabolism dysregulation, inhibition of erythropoietin formation, bleeding because of iatrogenic anticoagulation or disseminated intravascular coagulation can contribute to decreased haemoglobin levels [36]. Since ICU patients have a deeper decline in haemoglobin levels, data suggest that the drop is related to the severity of inflammation associated with SARS-CoV-2 infection. In a cross-sectional study including 601 COVID19 patients it was found that lower haemoglobin levels at presentation were associated with poorer prognosis [37]. In our study, lower haemoglobin levels were found in a group with $25(\mathrm{OH})$ vitamin D status less than $20 \mathrm{ng} / \mathrm{mL}$. This finding can support the hypothesis of the correlation between vitamin $\mathrm{D}$ deficiency and poorer prognosis.

A prospective observational study with 372 COVID-19 patients demonstrated that vitamin D deficiency was more prevalent in COVID-19 patients with severe clinical picture and serum level of inflammatory markers was found to be higher in patients with vitamin D deficiency [38]. Similarly, Adami et al. found that patients with arterial partial oxygen pressure $\left(\mathrm{PaO}_{2}\right)<60 \mathrm{mmHg}$ had significantly lower mean vitamin $\mathrm{D}$ status compared to patients with $\mathrm{PaO}_{2} \geq 60 \mathrm{mmHg}$. Also, in the study it was seen that vitamin $\mathrm{D}$ deficiency was associated with increased levels of CRP, increased risk of severe systemic inflammatory response and respiratory failure in COVID-19 patients [39]. In our study higher CRP levels were seen in vitamin D-deficient cases $(p=0.013)$. Procalcitonin levels were also found to be higher in the vitamin D-deficient groups that was not statistically significant.

D-dimer levels may increase for many reasons in the majority of patients with COVID-19. Increased pro-inflammatory cells can induce the dysfunction of endothelial cells, resulting in excess thrombin generation [40]. Hypoxia may stimulate thrombosis. Patients with more severe clinical picture of COVID-19 are usually elderly and have many comorbidities; thrombosis risk is higher in these patients. Disseminated intravascular coagulation can be seen in COVID-19 patients [41]. Zhang et al. demonstrated that D-dimer levels greater than $2.0 \mu \mathrm{g} / \mathrm{mL}$ (fourfold increase) on admission could effectively predict in-hospital mortality in patients with COVID-19. In other studies, markedly elevated $\mathrm{D}$-dimer levels were observed in those non-survivors $[42,43]$.

Some clinical reports demonstrated that deficiency of vitamin D leads to increased thrombosis, however, the exact mechanism is not known [44, 45]. In our study patients with markedly lower vitamin D status $(\leq 10 \mathrm{ng} / \mathrm{mL})$ had shown higher $\mathrm{D}$-dimer levels $(\mathrm{p}=0.025)$. This suggests that severe vitamin D deficiency can promote thrombosis in COVID-19 patients.

In a retrospective study with 212 COVID-19 patients in South Asian countries, it is demonstrated that there was a significant difference in the mean status of vitamin $\mathrm{D}$ within the mild, ordinary, severe and critical cases of COVID-19 [46]. Maghbooli et al. noticed that vitamin D sufficiency was associated with significant lower risk of hypoxia [47]. In a small cohort study it was observed that fewer COVID-19 patients who received oral doses of vitamin $D$ had required subsequent oxygen therapy compared to controls [48]. However, Murai et al. demonstrated that a single dose of $200000 \mathrm{IU}$ of cholecalciferol did not result in any clinically relevant effects or did not lead to reduce length of hospital stay among hospitalized patients with 
moderate-to-severe COVID-19 in the multicenter, doubleblind, randomized, placebo-controlled trial. But this finding can be attributed to the heterogeneity of the sample and geographic differences. Also, in this study, the patients were given a dose of cholecalciferol after a relatively long time from symptom onset to randomization [49]. Vitamin D status of the cases who needed oxygen therapy in our study were lower than those who did not need oxygen, which is not statistically significant $(p=0.05)$. Moreover, pneumonia was observed more frequently in patients who did not take vitamin D supplementation than patients who took vitamin D supplementation $(p=0.004)$.

Our study is a real-world study but has retrospective design. Vitamin D status evaluated in this study was measured within the last 6 months prior to the COVID-19 infection to minimise the influence of sunlight exposure or other factors that could affect $25(\mathrm{OH})$ vitamin D status. Studies with more recent vitamin D measures, such as taken at the time of hospital admission with symptoms of COVID-19 infection, should be done.

Some potential factors associated with COVID-19 severity and mortality are age, sex, body mass index, comorbidities and co-infection. This study did not assess the impact of comorbidities and co-infection on COVID19 patients. Risk factors such as socioeconomic status and behavioural factors that can have an impact on the clinical parameters of COVID-19 infections were not recorded. Our study had a single-centre design and had small sample size. Thus, larger studies should be done for more robust conclusions.

\section{Conclusion}

Increased inflammatory markers and adverse clinical outcomes of COVID-19 infection in vitamin D-deficient cases can be interpreted as increased risk of mortality and morbidity in COVID-19 patients is associated with lower vitamin D status. Vitamin D status may be a useful prognostic factor. Patients with prior vitamin D supplementation had shown lower incidence of pneumonia in this study. Patient with lower vitamin D status required more ventilation support. Like randomised trials and meta-analysis, our study had shown that vitamin D supplementation had positive effects against COVID infection. Therefore, administration of vitamin D supplementation can be recommended in cases with risk of COVID-19 infection or to COVID-19 patients.

Acknowledgements English language revision of this article has been supported by the Society of Endocrinology and Metabolism of Turkey

\section{Declarations}

Conflict of interest On behalf of all authors, the corresponding author states that there is no conflict of interest.

\section{References}

1. World Health Organization. Director-General's remarks at the media briefing on 2019-nCoV on 11 February 2020. (Accessed on February 12, 2020). http://www.who.int/dg/speeches/detail/ who-director-general-s-remarks-at-the-media-briefing-on-2019ncov-on-11-february-2020.

2. WHO Clinical management of severe acute respiratory infection when Novel coronavirus (nCoV) infection is suspected: interim guidance. (2020). https://www.who.int/internal-publicationsdetail/clinical-management-of severe-acute-respiratory-infectionwhen-novel-coronavirus-(ncov)- infection-is-suspected.

3. Chan JF, Yuan S, Kok KH et al (2020) A familial cluster of pneumonia associated with the 2019 novel coronavirus indicating person-to-person transmission: a study of a family cluster. Lancet 395:514-523

4. Yang X, Yu Y, Xu J et al (2020) Clinical course and outcomes of critically ill patients with SARS-CoV-2 pneumonia in Wuhan, China: a single-centered, retrospective, observational study. Lancet Respir Med 8:475-481

5. Wu Z, McGoogan JM. Characteristics of and Important Lessons From the Coronavirus Disease 2019 (COVID-19) Outbreak in China: Summary of aReport of 72314 Cases From the Chinese Center for Disease Control and Prevention. JAMA. 2020;323(13):1239-1242. https://doi.org/10.1001/jama.2020. 2648

6. Petrilli CM, Jones SA, Yang J et al (2020) Factors associated with hospital admission and critical illness among 5279 people with coronavirus disease 2019 in New York City: prospective cohort study. BMJ 369:1966

7. Richardson S, Hirsch JS, Narasimhan M et al (2020) Presenting characteristics, comorbidities, and outcomes among 5700 patients hospitalized with COVID-19 in the New York City area. JAMA 323:2052-2059

8. Onder G, Rezza G, Brusaferro S (2020) Case-fatality rate and characteristics of patients dying in relation to COVID-19 in Italy. JAMA 323:1775-1776

9. Kragholm K, Andersen MP, Gerds TA, et al (2020) Association between male sex and outcomes of Coronavirus Disease 2019 (Covid-19) - a Danish nationwide, register-based study.Clin Infect Dis 8:ciaa924. https://doi.org/10.1093/cid/ciaa924.

10. Price-Haywood EG, Burton J, Fort D, Seoane L (2020) Hospitalization and Mortality among Black Patients and White Patients with Covid-19. N Engl J Med 382:2534-2543

11. Food and Nutrition Board of the Institute of Medicine (1997) Vitamin D . Dietary reference intakes for calcium, phosphorus, magnesium, vitamin D, fluoride. National Academies Press, Washington, DC, p 250

12. Holick MF, Binkley NC, Bischoff-Ferrari HA et al (2011) Evaluation, treatment, and prevention of vitamin D deficiency: an endocrine society clinical practice guideline. J Clin Endocrinol Metab 96:1911-1930

13. Dawson-Hughes B, Mithal A, Bonjour JP et al (2010) IOF position statement: vitamin D recommendations for older adults. Osteoporos Int 21:1151

14. Ross AC, Taylor CL, Yaktine AL et al (2011) Dietary reference intakes for calcium and vitamin. Institute of medicine (US) 
committee to review dietary reference intakes for vitamin D and calcium. National Academies Press

15. Wacker M, Holick MF (2013) Vitamin D: effects on skeletal and extraskeletal health and the need for supplementation. Nutrients 5(1):111-148

16. Villamor E (2006) A potential role for vitamin D on HIV infection? Nutr Rev 64(5 Pt 1):226-233. https://doi.org/10.1301/nr. 2006.may

17. Ginde AA, Mansbach JM, Camargo CA Jr (2009) Association between serum 25 -hydroxyvitamin $\mathrm{D}$ level and upper respiratory tract infection in the Third National Health and Nutrition Examination Survey. Arch Intern Med 169(4):384-390

18. Cannell JJ et al (2006) Epidemic influenza and vitamin D. Epidemiol Infect 134(6):1129-1140

19. Bodnar LM, Krohn MA, Simhan HN (2009) Maternal vitamin D deficiency is associated with bacterial vaginosis in the first trimester of pregnancy. J Nutr 139(6):1157-1161

20. Rezaei R, Aslani S, Marashi M, Rezaei F, Sharif-Paghaleh E (2018) Immunomodulatory effects of vitamin D in influenza infection. Curr Immunol Rev 14(1):40-49

21. Ahmed A, Siman-Tov G, Hall G, Bhalla N, Narayanan A (2019) Human antimicrobial peptides as therapeutics for viral infections. Viruses 11:704

22. Barlow PG, Svoboda P, Mackellar A, Nash AA, York IA, Pohl J, Davidson DJ, Donis RO (2011) Antiviral activity and increased host defense against influenza infection elicited by the human cathelicidin. PLoS ONE 6:25333

23. Hughes DA, Norton R (2009) Vitamin D and respiratory health. Clin Exp Immunol 158(1):20-25. https://doi.org/10.1111/j.13652249.2009.04001.x

24. Ortega JT, Serrano ML, Pujol FH, Rangel HR (2020) Role of changes in SARS-CoV-2 spike protein in the interaction with the human ACE2 receptor: An in silico analysis. EXCLI J 19:410-417

25. Xu J, Yang J, Chen J, Luo Q, Zhang Q, Zhang H (2017) Vitamin D alleviates lipopolysaccharide-induced acute lung injury via regulation of the renin-angiotensin system. Mol Med Rep 16(5):7432-7438

26. Merzon E, Tworowski D, Gorohovski A et al (2020) Low plasma $25(\mathrm{OH})$ vitamin $\mathrm{D}$ level is associated with increased risk of COVID-19 infection: an Israeli population-based study. FEBS J 287:3693. https://doi.org/10.1111/febs.15495

27. Maghbooli Z, Sahraian MA, Ebrahimi M et al (2020) Vitamin D sufficiency, a serum 25-hydroxyvitamin D at least $30 \mathrm{ng} /$ $\mathrm{mL}$ reduced risk for adverse clinical outcomes in patients with COVID-19 infection. PLoS ONE 15:e0239799

28. Ali N (2020) Role of vitamin D in preventing of COVID19 infection, progression and severity. J Infect Public Health 13(10):1373-1380

29. Dankers W, Colin EM, van Hamburg JP, Lubberts E (2017) Vitamin D in autoimmunity: molecular mechanisms and therapeutic potential. Front Immunol 7:697

30. Infante M, Ricordi C, Sanchez J, Clare-Salzler MJ, Padilla N, Fuenmayor V (2019) Influence of vitamin d on islet autoimmunity and beta-cell function in type 1 diabetes. Nutrients 11:2185

31. Bouillon R, Marcocci C, Carmeliet G, Bikle D, White JH, Dawson-Hughes B (2019) Skeletal and extraskeletal actions of vitamin D: current evidence and outstanding questions. Endocrine Rev 40:1109-1151

32. Grant WB, Lahore H, McDonnell SL, Baggerly CA, French CB, Aliano JL (2020) Evidence that vitamin D supplementation could reduce risk of influenza and COVID-19 infections and deaths. Nutrients 12:988

33. Cantorna MT, Snyder L, Lin Y-D, Yang L (2015) Vitamin D and 1, $25(\mathrm{OH}) 2 \mathrm{D}$ regulation of T cells. Nutrients 7:3011-3021
34. Huang C, Wang Y, Li X, Ren L, Zhao J, Hu Y et al (2020) Clinical features of patients infected with 2019 novel coronavirus in Wuhan. China Lancet 395(10223):497-506

35. Liu J, Liu Y, Xiang P et al (2020) Neutrophil-to-lymphocyte ratio predicts critical illness patients with 2019 coronavirus disease in the early stage. J Transl Med 18:206

36. Weiss G, Ganz T, Goodnough LT (2019) Anemia of inflammation. Blood 133(1):40-50

37. Algassim, A.A., Elghazaly, A.A., Alnahdi, A.S. et al. Prognostic significance of hemoglobin level and autoimmune hemolytic anemia in SARS-CoV-2 infection. Ann Hematol. 2020.

38. Jain A, Chaurasia R, Sengar NS et al (2020) Analysis of vitamin D level among asymptomatic and critically ill COVID-19 patients and its correlation with inflammatory markers. Sci Rep 10:20191

39. Adami G, Giollo A, Fassio A, Benini C, Bertoldo E, Bertoldo F, Orsolini G, Idolazzi L, Viapiana O, Giannini S, Passeri G, Tacconelli E, Micheletto C, Gatti D, Rossini M (2021) Vitamin D and disease severity in coronavirus disease 19 (COVID-19). Reumatismo 72(4):189-196

40. Levi M, van der Poll T (2017) Coagulation and sepsis. Thromb Res 149:38-44

41. Tripodi A (2011) D-dimer testing in laboratory practice. Clin Chem 57:1256-1262

42. Guan WJ, Ni ZY, Hu Y et al (2020) China medical treatment expert group for $\mathrm{C}$. Clinical characteristics of coronavirus disease 2019 in China. N Engl J Med. https://doi.org/10.1056/NEJMo a2002032 (Epub ahead of print)

43. Tang N, Li D, Wang X, Sun Z (2020) Abnormal coagulation parameters are associated with poor prognosis in patients with novel coronavirus pneumonia. J Thrombosis Haemostasis: JTH 18:844-847

44. Khademvatani K, Seyyed-Mohammadzad MH, Akbari M, Rezaei Y, Eskandari R, Rostamzadeh A (2014) The relationship between vitamin D status and idiopathic lower-extremity deep vein thrombosis. Int J Gen Med 7:303-309

45. Wu WX, He DR (2018) Low vitamin D levels are associated with the development of deep venous thromboembolic events in patients with ischemic stroke. Clin Appl Thromb Hemost 24:69-75

46. Alipio M.Vitamin D Supplementation Could Possibly Improve Clinical Outcomes of Patients Infected with Coronavirus-2019 (COVID-19) (April 9, 2020). Available at SSRN: https://ssrn.com/ abstract $=3571484$.

47. Maghbooli Z, Sahraian MA, Ebrahimi M et al (2020) Vitamin D sufficiency, a serum 25-hydroxyvitamin D at least $30 \mathrm{ng} /$ $\mathrm{mL}$ reduced risk for adverse clinical outcomes in patients with COVID-19 infection. PLoS ONE 15(9):e0239799

48. Tan CW, Ho LP, Kalimuddin S, Cherng BPZ, Teh YE, Thien SY (2020) A cohort study to evaluate the effect of combination vitamin D. Magnesium and vitamin B12 (DMB) on progression to severe outcome in older COVID-19 patients. Infect Dis (except HIV/AIDS) 79-80:111017 (preprint)

49. Murai IH, Fernandes AL, Sales LP et al (2021) Effect of a single high dose of vitamin $\mathrm{D}_{3}$ on hospital length of stay in patients with moderate to severe COVID-19: a randomized clinical trial. JAMA $325: 1053$

Publisher's Note Springer Nature remains neutral with regard to jurisdictional claims in published maps and institutional affiliations. 